\title{
Twitch pressures in the assessment of diaphragm weakness
}

\author{
ANNE MIER, CONOR BROPHY, JOHN MOXHAM, MALCOLM GREEN \\ From the Department of Respiratory Muscle Physiology, Brompton Hospital, London
}

ABSTRACT To assess the value of phrenic nerve stimulation in the investigation of diaphragm function, transdiaphragmatic pressures were measured in 20 healthy subjects and in 15 patients with diaphragm weakness, during unilateral and bilateral transcutaneous phrenic nerve stimulation at $1 \mathrm{~Hz}$ at functional residual capacity (twitch Pdi). Diaphragm function was initially assessed by measuring transdiaphragmatic pressure during a voluntary manoeuvre, the maximal sniff (sniff Pdi); normal readings were confirmed in the control subjects (102-157 (normal >98) $\mathrm{cm} \mathrm{H}_{2} \mathrm{O}$ in the 10 men, 79-102 (normal >70) $\mathrm{cm} \mathrm{H}_{2} \mathrm{O}$ in the 10 women) and reduced values were found in the 15 patients with diaphragm weakness $\left(7 \cdot 5-90 \mathrm{~cm} \mathrm{H}_{2} \mathrm{O}\right.$ in the $13 \mathrm{men}, 23$ and $53 \mathrm{~cm} \mathrm{H}_{2} \mathrm{O}$ in the two women). Twitch Pdi during bilateral phrenic nerve stimulation ranged from 8.8 to $33 \mathrm{~cm} \mathrm{H}_{2} \mathrm{O}$ in the control subjects and from $3 \cdot 1$ to $27 \mathrm{~cm} \mathrm{H}_{2} \mathrm{O}$ in the 10 patients in whom a measurement could be obtained. Bilateral twitch Pdi correlated with sniff Pdi both in the control subjects and in the patients with diaphragm weakness $(r=0 \cdot 75)$. Only four patients had a bilateral twitch Pdi below the lowest value seen in the control group, including the three with the lowest sniff Pdi $\left(3 \cdot 1-8 \cdot 5 \mathrm{~cm} \mathrm{H}_{2} \mathrm{O}\right)$. These results indicate that transdiaphragmatic pressure recorded during bilateral phrenic nerve stimulation discriminated between control subjects and patients with known weakness of the diaphragm only when this was severe.

\section{Introduction}

In the assessment of patients with suspected diaphragm weakness transdiaphragmatic pressures have been recorded during various maximal voluntary manoeuvres. ${ }^{1-4}$ Maximal static respiratory efforts may, however, be limited by reflex inhibition, ${ }^{56}$ by subjective discomfort, and by haemodynamic changes. ${ }^{7}$ Furthermore, these manoeuvres are dependent on the cooperation of the subject, and electromyographic studies have indicated that the diaphragm may not be maximally activated despite "maximal" inspiratory efforts. ${ }^{8}$ More objective methods of assessing the strength of the diaphragm have therefore been sought.

Percutaneous stimulation of the phrenic nerves using intermittent electrical impulses was described in $1951^{9}$ as a method of providing artificial respiration. Attempts were made subsequently to measure diaphragm strength by means of phrenic nerve stimula-

Address for reprints requests: Dr Anne Mier, Department of Medicine, Charing Cross Hospital, London W6 8RF.

Accepted 22 September 1989 tion but frequencies of up to $100 \mathrm{~Hz}$ were required to activate the diaphragm maximally. ${ }^{10} 11$ Such tetanic stimulation was painful, resulted in contraction of the neck muscles, and could not be used in the routine investigation of patients. Recently transdiaphrag- $\frac{x}{\sigma}$ matic pressure (Pdi) has been assessed in normal 3 subjects during phrenic nerve stimulation ${ }^{12-16}$ at stimulation frequencies of $1 \mathrm{~Hz}$ (twitch Pdi). This investigation has been found to be useful in confirming $\mathrm{O}$ and quantifying hemidiaphragm dysfunction in patients with recent hemidiaphragm paralysis. ${ }^{17} \mathrm{Al}-\frac{\mathrm{O}}{3}$ though phrenic nerve stimulation has also been performed during maximal static inspiratory efforts to 0 quantify maximal diaphragmatic contraction, ${ }^{18}$ this $N$ technique is not always easily applied in the study of N patients.

The present studies were carried out to determine whether twitch Pdi would provide a quantitative measure of diaphragm strength in the routine inves- $\stackrel{\mathcal{\Phi}}{?}$ tigation of patients with muscle weakness. Transdia- 0 phragmatic pressures generated during phrenic nerve stimulation were compared with those recorded dur- $\mathbb{\mathbb { D }}$ ing a voluntary manoeuvre, the maximal sniff, which $\frac{\Omega}{\mathbb{D}}$ was selected because it has been shown to be easily performed, reproducible, ${ }^{19}$ and capable of detecting different gradations of diaphragm weakness. ${ }^{20}$ 
Methods

\section{SUBJECTS}

Measurements were made on twenty control subjects (10 men, 10 women) aged 24-73 (mean 47) years. Their height ranged from 153 to 183 (mean 167) cm and their weight from 48 to 92 (mean 67) $\mathrm{kg}$. They had normal respiratory function and gave no history of neuromuscular disease.

Studies were also performed on 15 patients $(13 \mathrm{men}$, two women) aged 30-73 (mean 50) years with dyspnoea and diaphragm weakness. Their height ranged from 157 to 178 (mean 170) cm and weight from 35 to 81 (mean 63) kg. Two patients had muscular dystrophy and one patient had each of the following: polyarteritis nodosa, Tolosa-Hunt syndrome (treated with corticosteroids), poliomyelitis in childhood affecting the right leg and respiratory muscles, surgical trauma to the phrenic nerves six months previously, polymyositis diagnosed on the basis of muscle biopsy, and thyrotoxic myopathy (reversed after treatment with carbimazole). In the remaining seven patients myopathy was of unknown aetiology. Six of the 15 patients had generalised muscle weakness affecting all muscle groups. Patients with muscle weakness due to abnormal neuromuscular transmission (myasthenia gravis) were excluded. All subjects gave informed consent to the studies, which had the approval of the local ethical committee.

\section{MEASUREMENTS}

Two pairs of linearised magnetometer coils (Norman $\mathrm{H}$ Peterson, Boston, Massachusetts) were placed at the level of the fifth intercostal space (to measure the rib cage anteroposterior diameter) and $2 \mathrm{~cm}$ above the umbilicus (to monitor change in abdominal anteroposterior dimensions). Magnetometer signals were calibrated in $0.5 \mathrm{~cm}$ steps along a linear scale before and after the studies.

Diaphragm muscle action potentials ( $M$ waves) were recorded with surface electrodes (Nikomed 460) placed in the seventh or eighth intercostal spaces 2$3 \mathrm{~cm}$ from the costal margin on either side after the skin had been carefully prepared with an abrasive cleanser and isopropyl alcohol. A reference electrode was placed on the outer aspect of the ipsilateral arm. Diaphragm electromyogram (EMG) signals were processed with an amplifier (Medelec PA 63) and were filtered below $16 \mathrm{~Hz}$ and above $1600 \mathrm{~Hz}$.

Oesophageal (Poes) and gastric $(\mathrm{Pg})$ pressures $^{5}$ were measured with latex balloon catheters (PK Morgan 71510) coupled to Validyne differential pressure transducers (MP 45-1; range $\pm 150 \mathrm{~cm}_{2} \mathrm{O}$ ). The oesophageal balloon was positioned in the mid oesophagus and filled with $0.5 \mathrm{ml}$ air. ${ }^{21}$ The tip of the gastric balloon was positioned $65 \mathrm{~cm}$ from the nares and filled with $1.5 \mathrm{ml}$ air. Transdiaphragmatic pressure (Pdi) was obtained by electronic subtraction of Poes from $\mathrm{Pg}$. Pdi at resting end expiration (FRC) was used as a zero reference point.

\section{PROTOCOL}

Pdi was measured during a series of sharp maximal sniffs performed from resting end expiration (FRC) without a noseclip in the seated posture. After a short learning period 10 maximal sniffs were recorded with suitable rest pauses between them. ${ }^{19}$ The highest Pdi value obtained from the 10 sniffs was taken as a measure of voluntary diaphragmatic strength. ${ }^{19} 20$

Phrenic nerve stimulation was then performed with the subject wearing a noseclip, supine, on a couch with one pillow. The phrenic nerves were stimulated percutaneously, at the posterior border of the sternomastoid muscle at the level of the cricoid cartilage, ${ }^{22}$ by two pairs of bipolar surface stimulating electrodes (Medelec 53054) with felt tips $5 \mathrm{~mm}$ in diameter. The electrodes were attached to a dual output isolated stimulator (Digitimer 3072) so that each phrenic nerve could be stimulated in isolation or both together. The stimulator produced square wave impulses $0.1 \mathrm{~ms}$ in duration at a frequency of $1 \mathrm{~Hz}$. The diaphragm EMG signals and Pdi traces were displayed on a Tektronix $5103 \mathrm{~N}$ storage oscilloscope. The voltage of stimulation was raised until there was no further increase either in the size of the diaphragm muscle action potential or in twitch height measured on the Pdi trace. The voltage used was increased by a further $10 \%$ to ensure supramaximal stimulation (80-160 volts).

In each case the right phrenic nerve was stimulated first (right twitch). The subject was instructed to breathe in and out several times and then to relax at the resting end of a breath, close the mouth firmly, and keep the back of the throat closed while three to six twitches were recorded. After a few breaths the procedure was repeated until at least 10 adequate twitches with traces that could be analysed had been recorded (for which 20-40 twitches had to be recorded). After a rest of two to five minutes the procedure was repeated with stimulation of the left phrenic nerve (left twitch) and then with stimulation of both phrenic nerves simultaneously (bilateral twitch).

Between day variability of the technique was determined by repeating the measurements in four control subjects on six separate days over 14-17 months. Within day variability was assessed by recording at least 20 twitches during three separate runs separated by 30 minutes on one day.

Finally, the right phrenic nerve was stimulated tetanically in three control subjects after local infiltration of the underlying skin with $1 \mathrm{ml} 1 \%$ lignocaine to reduce local discomfort. Stimulation was performed at FRC with frequencies of $100 \mathrm{~Hz}$ for two to three 


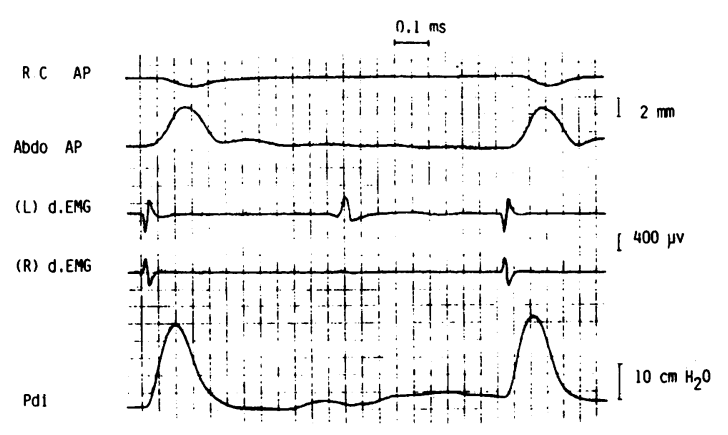

Fig 1 Electrical and mechanical responses of the diaphragm during bilateral phrenic nerve stimulation at relaxed end expiration in one control subject. Ribcage (RCAP) and abdominal (AbdoAP) anteroposterior dimensions were recorded with linearised magnetometers, and electromyograms of left $((L)$ d.Emg) and right $((R)$ d.Emg) hemidiaphragms were obtained with surface electrodes. Transdiaphragmatic pressure (Pdi) is shown on the bottom trace.

seconds. The height of plateau Pdi, maintained for one second, was measured.

All signals were displayed on an eight channel strip chart recorder (Mingograph 800, Siemens) and stored. on a magnetic tape recorder (Racal Store 7) with a frequency response of up to $5000 \mathrm{~Hz}$ for later playback and analysis.

Phrenic nerve terminal motor latency was measured as the time from the stimulus to the onset of the $M$ wave. ${ }^{22}$ The height of deflection on the Pdi trace during a single stimulus was measured as twitch Pdi. Any twitch during which the diaphragm muscle action potential was not maximal, indicating that the electrode position in the neck was not optimal, was discarded. Only twitches that were performed at FRC, as shown by magnetometer and Pdi tracings, were measured.

STATISTICAL ANALYSIS

Group data are expressed as means with standard deviations in parentheses. Differences were tested for significance by the two tailed paired or unpaired Student's $t$ test as appropriate. Simple correlations were obtained by means of the Pearson correlation coefficient. Multiple linear regression analysis was performed to investigate the relation between twitch amplitude and subjects' age, height, and mass. ${ }^{23}$

\section{Results}

\section{CONTROL SUBJECTS}

\section{Phrenic nerve stimulation}

Stimulation of both phrenic nerves was successful in all 20 control subjects. No problems were experienced with the technique of relaxing at FRC with a closed glottis. Records obtained during bilateral stimulation in one subject are shown in figure 1. Stimulation of either phrenic nerve alone resulted in a diaphragm muscle action potential on the side of stimulation and a reduction in rib cage and increase in abdominal anteroposterior dimensions. No electrical response was recorded from the contralateral side. The maximal $M$ wave amplitude varied from 0.3 to $1.5 \mathrm{mv}$; it was highly reproducible within a given study, but varied both between subjects and within a given subject when studied on different days. By contrast, phrenic nerve terminal motor latency was similar among the subjects $(6.8(0.75) \mathrm{ms})$ and was highly repeatable (coefficient of variation within subjects between days $4.5 \%$ $(1 \cdot 7 \%))$.

Results obtained in the 20 control subjects are summarised in the table. Stimulation of the lef phrenic nerve resulted in a significantly larger twitch Pdi than stimulation of the right nerve in all but two cases (mean difference $2.4 \mathrm{~cm} \mathrm{H}_{2} \mathrm{O}^{*}$; $\mathrm{p}<0.001$ ). Similarly, bilateral twitch Pdi was larger than the sum of Pdi obtained during unilateral right and left phrenic nerve stimulation $(\mathfrak{p}<0.001)$. Unilateral and bilateral twitch Pdi were correlated $(r=0 \cdot 56)$. There

$* 1 \mathrm{~cm} \mathrm{H}_{2} \mathrm{O}=10 \cdot 2 \mathrm{kPa}$.

Unilateral and bilateral "twitch" transdiaphragmatic pressure (Pdi), "sniff" Pdi and twitch Pdi:sniff Pdi ratio in 20 control subjects and 10 patients with diaphragm weakness

\begin{tabular}{|c|c|c|c|c|c|c|c|}
\hline & \multicolumn{3}{|c|}{ Twitch Pdi $\left(\mathrm{cm} \mathrm{H}_{2} \mathrm{O}\right)$} & \multirow{2}{*}{$\begin{array}{l}\text { Sniff Pdi } \\
\left(\mathrm{cm} \mathrm{H}_{2} \mathrm{O}\right)\end{array}$} & \multicolumn{3}{|c|}{ Twitch Pdi:Sniff Pdi (\%) } \\
\hline & Right & Left & Bilateral & & Right & Left & Bilateral \\
\hline $\begin{array}{l}\text { CONTROLS } \\
\text { Mean } \\
\text { SD } \\
\text { Range }\end{array}$ & $\begin{array}{l}8 \cdot 1 \\
2 \cdot 4 \\
3 \cdot 8-12 \cdot 4 \\
p<0 \cdot 001\end{array}$ & $\begin{array}{l}10 \cdot 5 \\
2 \cdot 3 \\
5 \cdot 3-15 \cdot 3\end{array}$ & $\begin{array}{l}20 \cdot 7 \\
5 \cdot 3 \\
8 \cdot 8-33 \cdot 1\end{array}$ & $\begin{array}{l}114 \cdot 9 \\
22 \cdot 7 \\
79-157\end{array}$ & $\begin{array}{l}7 \cdot 2 \\
1 \cdot 9 \\
3 \cdot 2-10.7\end{array}$ & $\begin{array}{l}9 \cdot 2 \\
1 \cdot 7 \\
5 \cdot 8-13 \cdot 2\end{array}$ & $\begin{array}{l}18 \cdot 3 \\
4 \cdot 0 \\
10 \cdot 7-25 \cdot 6\end{array}$ \\
\hline $\begin{array}{l}\text { WEAK PATIENTS } \\
\text { Mean } \\
\text { SD } \\
\text { Range }\end{array}$ & $\begin{array}{l}4.1 \\
3.7 \\
0.5-11.4 \\
p<0.05\end{array}$ & $\begin{array}{l}6 \cdot 7 \\
4 \cdot 2 \\
0 \cdot 5-15 \cdot 7\end{array}$ & $\begin{array}{l}15 \cdot 1 \\
9 \cdot 4 \\
3 \cdot 1-26 \cdot 8\end{array}$ & $\begin{array}{l}53 \cdot 9 \\
31 \cdot 2 \\
7 \cdot 5-90\end{array}$ & $\begin{array}{l}6 \cdot 7 \\
3 \cdot 4 \\
2 \cdot 2-13 \cdot 0\end{array}$ & $\begin{array}{l}10 \cdot 5 \\
4 \cdot 7 \\
2 \cdot 2-16 \cdot 8\end{array}$ & $\begin{array}{l}22 \cdot 7 \\
6 \cdot 9 \\
8 \cdot 8-28 \cdot 2\end{array}$ \\
\hline
\end{tabular}




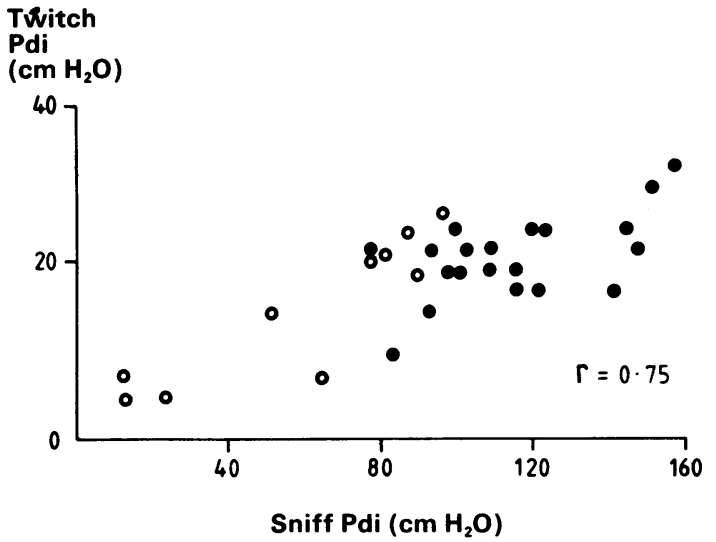

Fig 2 Relation of transdiaphragmatic pressures recorded during phrenic nerve stimulation (bilateral) and during a maximal sniff (sniff Pdi) in control subjects (○) and patients with diaphragm weakness $(O)$.

was no relation between the amplitude of twitch pressures and subjects' age, height, or mass.

Although the amplitude of twitch Pdi varied between subjects (table), it was repeatable within each subject on a given day. There was no consistent trend towards an increase or decrease in twitch Pdi amplitude with repeated measures either between or within days. The within run coefficients of variation in the 20 control subjects were $10 \%, 10 \%$, and $8 \%$ for right, left, and bilateral twitch Pdi. In the four control subjects studied repeatedly over several months, within day coefficients of variation for right, left, and bilateral twitch Pdi were 6\%,7\%, and 5\%; between day coefficients of variation were $8 \%, 7 \%$, and $7 \%$.

Transdiaphragmatic pressures obtained during tetanic stimulation of the right phrenic nerve in three control subjects were 46,48 , and $49 \mathrm{~cm} \mathrm{H}_{2} \mathrm{O}$. Twitch: tetanus ratios were $19 \cdot 5 \%, 20 \cdot 5 \%$, and $22 \cdot 0 \%$.

\section{Sniff manoeuvre}

Sniff Pdi in the 10 men ranged from 102 to 157 (mean 128; normal > 98) $\mathrm{cm} \mathrm{H}_{2} \mathrm{O}$ and in the 10 women from 79 to 120 (mean 102; normal > 70) $\mathrm{cm} \mathrm{H}_{2} \mathrm{O}^{19}$

Right and left twitch Pdi were correlated with sniff Pdi $(r=0.46$ and 0.65$)$. The relation between bilateral twitch Pdi and sniff Pdi is illustrated in figure 2.

\section{PATIENTS WITH DIAPHRAGM WEAKNESS \\ Phrenic nerve stimulation}

Phrenic nerve stimulation was well tolerated by all patients who were able to relax with a closed glottis at FRC. The patient with the greatest diaphragm weakness had muscular dystrophy and a sniff Pdi of $7.5 \mathrm{~cm}$ $\mathrm{H}_{2} \mathrm{O}$. Both nerves were inexcitable in this patient; neither a diaphragm muscle action potential nor a transdiaphragmatic pressure response could be obtained during stimulation. In two further patients, in whom a small muscle action potential was recorded $(0.10$ and $0.17 \mathrm{mV})$, no detectable Pdi trace was obtained during phrenic nerve stimulation. Only one nerve could be excited in two further patients. The 10 remaining patients had both phrenic nerves stimulated and their results were used in the analysis.

As in the control subjects, the amplitude of left twitch Pdi in the 10 patients was larger than that of the right $(p<0.05)$. Similarly, Pdi recorded during bilateral phrenic nerve stimulation was larger than the sum of the Pdi values obtained during individual stimulation of the right and left phrenic nerves alone $(\mathrm{p}<0.01)$.

\section{Sniff manoeuvre}

Sniff Pdi ranged from 7.5 to $90\left((\right.$ mean 60$\left.) \mathrm{cm} \mathrm{H}_{2} \mathrm{O}\right)$ in the 13 male patients, and was 23 and $53 \mathrm{~cm} \mathrm{H}_{2} \mathrm{O}$ in the two women. These values were below the normal lower limits (male 98, female $70 \mathrm{~cm} \mathrm{H}_{2} \mathrm{O}^{19}$ ) and confirmed the presence of moderate to severe diaphragm weakness in all 15 patients.

Although the response to bilateral twitch in the patients was lower than in the control subjects (table) the difference was not significant $(p=0.48)$. Six patients, all with mild weakness (as defined by sniff Pdi) had bilateral twitch Pdi values that overlapped the values from the control subjects (fig 2: bilateral twitch Pdi shown on $y$ axis). Bilateral twitch Pdi was below the control range in the three weakest patients and unilateral twitch Pdi was abnormally low in three. Bilateral twitch Pdi was related to sniff Pdi ( $r=$ $0 \cdot 75$ :fig 2).

\section{Discussion}

The purpose of these studies was to determine whether diaphragm contractility and hence diaphragm strength could be assessed by measuring the amplitude of twitch Pdi in patients with muscle weakness. Although twitch Pdi has been measured in normal subjects, its usefulness as a clinical test in the study of patients with muscle weakness has not previously been investigated.

As the pressure developed by the diaphragm depends on muscle length and geometry, ${ }^{24}$ we attempted to perform phrenic nerve stimulation at constant diaphragm length ${ }^{25}$ during relaxation at FRC with a closed glottis. Stimulation studies were therefore performed in the supine posture to minimise alterations of body position and hence of ribcage configuration. Ribcage and abdominal dimensions were monitored to ensure that subjects returned to the same configuration during each stimulation. The abdomen was not restricted by strapping as this is impracticable and 
poorly tolerated by patients. By contrast, sniffs were recorded in the seated posture since the coordinated maximal effort of a sniff appears to be more difficult for patients when supine. Sniff Pdi has been found to be significantly smaller in the supine posture ${ }^{26}$ despite an expected improvement in mechanical advantage caused by the increase in diaphragm length. Thus, although "supine" twitch Pdi was compared with "seated" sniff Pdi, these postures were standardised throughout the studies and recordings of twitch Pdi: sniff Pdi ratios were found to be repeatable.

Twitch pressure depends not only on muscle length but also on the voltage applied to the phrenic nerves. We checked that stimuli were maximal by monitoring the amplitude of diaphragm muscle action potentials recorded by surface EMG. There was a small variation in the size of twitch Pdi, but the within subject repeatability was similar to that reported for measurements of strength in other skeletal muscles ${ }^{27}$ and in respiratory muscles ${ }^{192}$ and for routine lung function tests. ${ }^{29}$

Twitch pressures obtained in the control subjects were of similar size to those recorded by other workers using surface ${ }^{1214}$ and needle electrodes. ${ }^{13}$ Right, left, and bilateral twitch pressures obtained with surface electrodes were reproducible between days in the four control subjects. Similarly, phrenic nerve terminal motor latency was similar in the subjects, as found by previous workers, and was repeatable. ${ }^{1223031}$ By contrast, the maximum $M$ wave amplitude was reproducible within a study but varied both between subjects and within a given subject studied on different days. $^{12230}$ No electrical response was recorded during phrenic nerve stimulation from the contralateral side, confirming previous reports concerning the $\mathrm{cat}^{32}$ and man. ${ }^{30}$

The observation that left twitch Pdi was larger than right twitch Pdi has been noted before. ${ }^{16}$ This difference was seen in both right and left handed subjects. Consequently, hypertrophy of neck muscles on the right seems unlikely to have prevented the stimulus current from reaching the right phrenic nerve. Similarly, gastric pressure recorded during twitches of the left phrenic nerve was not always larger than during right phrenic nerve stimulation. This indicated that the difference in transdiaphragmatic pressures did not arise because gastric pressure provided a more accurate indication of the action of the left hemidiaphragm. Although we have no experimental evidence for this, a possible reason for the difference in pressures may be a difference in compliance between the two hemithoraces, the compliance of the left being reduced by the presence of the heart.

As previously noted,${ }^{17}$ unilateral stimulation of the right and left phrenic nerves separately provided valuable information about the function of each hemidiaphragm. Although both hemidiaphragms $\stackrel{+}{-}$ appeared to be affected equally in most weak patients, 든 right twitch amplitude was much less than left twitch Pdi in one patient. In two other cases twitch Pdi was $\widehat{D}$ obtained only on one side. This indicates that a disease process may affect the two sides to a different degrees and confirmed that in patients each hemidiaphragm. should be studied separately.

Nevertheless, bilateral twitch Pdi provided a better $\vec{\omega}$ indication of overall diaphragm strength. During unilateral phrenic nerve stimulation the stimulated hemidiaphragm descends while the contralateral ${ }^{+}$ hemidiaphragm ascends. ${ }^{33}$ Consequently, the pressureñ generated during a unilateral twitch will be affected by 8 the compliance both of the unstimulated hemidiaphragm and of the abdominal wall. The fact that such? distortion of the diaphragm is minimised when the hemidiaphragms contract together explains why® bilateral twitch Pdi is greater than the sum of right and@ left twitch Pdi obtained separately. Thus bilateral twitch Pdi provides a more accurate indication of ${ }^{\mathbb{D}}$ overall diaphragm strength than pressures obtained $\overrightarrow{0}$ during isolated unilateral stimulation.

We were concerned about the possibility that not all phrenic nerve motor fibres were being excited duringo transcutaneous stimulation. Previous studies in vitro, however, have shown that the force generated by aO skeletal muscle fibre during a single supramaximal $\frac{}{\varnothing}$ twitch ranges from $20 \%$ to $30 \%$ of the force generated $\varrho$ during a maximal tetanic stimulation. ${ }^{34}$ We found thatō twitch Pdi obtained in three control subjects during unilateral right phrenic nerve stimulation was $20.7 \%$ (SD $1.2 \%$ ) of that generated during tetanic stimulation of the same nerve; it has previously been shown that stimulation frequencies of $60-100 \mathrm{~Hz}$ are required to obtain a transdiaphragmatic pressure matching ${ }_{\sigma}^{\times}$ that of a maximal voluntary contraction. Bilateral 3 supramaximal tetanic phrenic nerve stimulation wasi not attempted because local pain, simultaneous stimulation of the brachial plexus, and local contrac- -0 tion of the underlying scalene muscles make this difficult to sustain. ${ }^{16}$ Although pressures produced during a maximal sniff may not be as high as those generated during a two step Mueller manoeuvre, ${ }^{4}$ the $N$ volley of impulses that passes along the phrenic nerven during a maximal sniff may resemble a brief tetanic stimulation. Indeed, we found that overall bilateral ${ }^{\omega}$ twitch Pdi in the control subjects averaged $18.3 \%$ of the maximal sniff Pdi. This value lies close to the twitch:tetanus ratio reported for isolated diaphragm muscle strips studied in vitro ${ }^{2535}$ and is compatible with ${ }_{+}^{+}$ the excitation of most, if not all, phrenic nerve fibres during transcutaneous phrenic nerve stimulation. This good correlation also lends support to the suggestion $\frac{\mathbb{P}}{\mathbb{D}}$ that twitch Pdi provides a useful indication of dia- $\varrho$ phragm contractility. 
Diaphragm function may be assessed by recording transdiaphragmatic pressure during various kinds of maximal voluntary effort. ${ }^{1-4}$ We chose to use the sniff manoeuvre in this group of patients, as it is rapidly learnt, easily performed, and reproducible, ${ }^{19}$ and does not require a noseclip or produce subjective discomfort. Sniff Pdi is reduced below the normal range in patients with respiratory muscle weakness, and is a simple and reliable method of assessing diaphragmatic strength. ${ }^{20}$

The finding that bilateral twitch Pdi among the patients as a group averaged $22.7 \%$ of the maximal sniff Pdi indicated that pressures generated during twitch and sniff in these patients were reduced in similar proportions. This observation would be expected in lower motorneurone lesions. Indeed, the cause of diaphragm weakness in our patients was consistent with an abnormality of either the anterior horn cell, the phrenic nerve, or the diaphragm muscle itself. A low sniff Pdi might also be caused by the patient's lack of volition or cooperation. A reduced twitch Pdi therefore in patients with a low sniff Pdi will help to confirm that lower motorneurone weakness is indeed present and that weakness is not due to a central cause or lack of cooperation.

Although the cerebral representation of the diaphragm is not known, it appears likely that diaphragm weakness could be caused by a lesion situated above the anterior horn cell. If measures of diaphragm strength were made in such a patient, sniff Pdi, which requires normal upper motorneurone function, would be reduced. Provided that the lower motorneurones were intact, however, the amplitude of twitch Pdi would by contrast be in the normal range. This combination of a reduced sniff Pdi with a normal twitch Pdi has been found in patients with cerebellar lesions ${ }^{36}$ and shows that performing both investigations may provide more information than either test alone.

Owing to the wide range of values found for twitch Pdi in the control subjects, there was an overlap of twitch pressures between the controls and the patients with diaphragm weakness (fig 2). The amplitude of bilateral twitch Pdi was reduced below the control range in only four patients, three of them with the lowest sniff Pdi. Similarly, because of the variability of twitch:sniff Pdi ratios, sniff Pdi, and hence voluntary diaphragm strength, could be estimated reliably from the amplitude of twitch Pdi in these three weakest patients only. Thus the use of bilateral twitch Pdi may not detect patients in whom diaphragm weakness is mild or moderate.

In conclusion, bilateral twitch Pdi was correlated with sniff Pdi in patients with diaphragm weakness and control subjects and helped to confirm that weakness detected by low values of sniff Pdi was neither volitional nor due to an upper motorneurone lesion. Measurement of twitch Pdi alone, however, discriminated between the control subjects and the patients only when diaphragm weakness was severe. Unilateral twitch Pdi provided additional information about the individual function of the two hemidiaphragms, and identified some patients where the lesions principally affected the right or the left side. The technique was well tolerated and played a useful part in the quantitative evaluation of patients with suspected severe diaphragmatic weakness.

AM was supported by the Medical Research Council and $\mathrm{CB}$ was supported by Napp Laboratories.

\section{References}

1 De Troyer A, Estenne M. Limitations of measurement of transdiaphragmatic pressure in detecting diaphragm weakness. Thorax 1981;36:169-74.

2 Newsom Davis J, Goldman M, Loh L, Casson M. Diaphragm function and alveolar hypoventilation. $Q J$ Med 1976;45:87-100.

3 Loh L, Goldman M, Newson Davis, J. Assessment of diaphragm function. Medicine (Baltimore) 1977;56: 165-9.

4 Laporta D, Grassino A. Assessment of transdiaphragmatic pressure in humans. J Appl Physiol 1985;58: 1469-76.

5 Agostoni E, Rahn H. Abdominal and thoracic pressures at different lung volumes. J Appl Physiol 1960;15: 1087-92.

6 Gibson GJ, Clark E, Pride NB. Static transdiaphragmatic pressure in normal subjects and in patients with chronic hyperinflation. Am Rev Respir Dis 1981;124:685-9.

7 Milic-Emili J, Orzalesi MM, Cook CD, Turner JM. Respiratory thoraco-abdominal mechanics in man. $J$ Appl Physiol 1964;19:217-23.

8 Agostoni E, Mead J. Statics of the respiratory system. In: Fenn WO, Rahn M, eds. Handbook of physiology, sect. 3, vol 1. Baltimore: Williams and Wilkins, 1964: $387-409$.

9 Sarnoff SJ, Sarnoff LC, Whittenberger J. Electrophrenic respiration VII. The motor point of the phrenic nerve in relation to external stimulation. Surg Gynaecol Obstet 1951;93:190-6.

10 Aubier M, Farkas G, De Troyer A, Mozes R, Roussos C. Detection of diaphragmatic fatigue in man by phrenic stimulation. J Appl Physiol 1981;50:538-44.

11 Moxham J, Morris A, Spiro S, Edwards R, Green M. Contractile properties and fatigue of the diaphragm in man. Thorax 1981;36:164-8.

12 Bellemare F, Bigland-Ritchie B. Assessment of human diaphragmatic strength and activation using phrenic nerve stimulation. Respir Physiol 1984;58:263-77.

13 Aubier M, Murciano D, Lecocguic J, Viires N, Pariente R. Bilateral phrenic nerve stimulation: a simple technique to assess diaphragm fatigue in humans. $J$ Appl Physiol 1985;58:58-64. 
14 McKenzie DK, Gandevia SC. Phrenic nerve conduction times and twitch pressures of the human diaphragm. $J$ Appl Physiol 1985;58:1496-504.

15 Moxham J, Miller J, Wiles CM, Green M. Effect of aminophylline on the human diaphragm. Thorax 1985;40:288-92.

16 Bellemare F, Bigland-Ritchie B, Woods J. Contractile properties of the human diaphragm in vivo. $J$ Appl Physiol 1986;61:1153-61.

17 Laroche C, Mier A, Moxham J, Green M. Diaphragm strength in patients with recent hemidiaphragm paralysis. Thorax 1988;43:170-4.

18 Gandevia SC, McKenzie DK. Activation of the human diaphragm during maximal static efforts. $J$ Physiol 1983;367:45-56.

19 Miller J, Moxham J, Green M. The maximal sniff in assessment of diaphragm function in man. Cli Sci 1985;69:91-6.

20 Mier A, Brophy C, Moxham J, Green M. Assessment of diaphragm weakness. Am Rev Respir Dis 1988; 137:877-83.

21 Milic-Emili J, Mead J, Turner JM, Glauser EM. Improved technique for estimating pleural pressure from oesophageal balloons. J Appl Physiol 1964;19:207-11.

22 Newsom Davis $J$, Phrenic nerve conduction in man. $J$ Neurol Neurosurg Psychiatry 1967;30:420-6.

23 Ryan B, Joiner B, Ryan T. Multiple regression. Minitab handbook. 2nd ed. Boston: Duxbury Press, 1985: 236-45.

24 Grassino A, Goldman M, Mead J, Sears T. Mechanics of the human diaphragm during voluntary contractions: statics. J Appl Physiol 1978;44:829-39.

25 McCully KK, Faulkner JA. Length-tension relationship of mammalian diaphragm muscles. J Appl Physiol 1983;54:1681-6.

26 Mulvey D, Koulouris $\mathrm{N}$, Goldstone J, Carrol M, Moxham J, Green M. The effect of posture on sniff transdiaphragmatic pressure. Eur Respir J 1988;1 (suppl):865.

27 Tornvall G. Assessment of physical capabilities with special reference to the evaluation of maximal volun- $\odot$ tary isometric muscle strength and maximal working capacity. Acta Physiol Scand 1963;58 (suppl 201).

28 Wilson SH, Cooke N, Edwards R, Spiro S. Predicted normal values for maximal respiratory pressures in caucasian adults and children. Thorax 1984;39:533-8.

29 Cotes JE. Lung function: assessment and application in medicine. 4th ed. Oxford: Blackwell, 1979:318.

30 De Troyer A, Vanderhoeft P. Phrenic nerve function after pneumonectomy. Chest 1981;2:212-4.

31 Maclean IC, Mattioni TA. Phrenic nerve conduction 윽 studies: a new technique and its application in quadri- plegic patients. Arch Phys Med Rehab 1981;62:70-3.

32 Sant'Ambrogio G, Frazier D, Wilson M, Agostoni E. Motor innervation and pattern of activity of cat diaphragm. J Appl Physiol 1963;18:43-6.

33 Mertun PA. Voluntary strength and fatigue. $J$ Physiol (Lond) 1954;123:553-64.

34 Close RI. Dynamic properties of muscle. Physiol Rev 1972;52:129-97.

35 Farkas G, Roussos C. Adaptability of the hamster diaphragm to exercise and/or emphysema. J Appl Physiol 1982;53:1263-72.

36 Mier A, Green M. Respiratory muscle weakness associated with cerebellar atrophy. Am Rev Respir $\mathbb{D}$ 1988;137:673-7. 